\title{
Excessive and Problematic Smartphone Use and Poor Mental Health in Adolescents
}

\author{
Young Gyu Cho* \\ Department of Family Medicine, Inje University Seoul Paik Hospital, Inje University College of Medicine, Seoul, Korea
}

\section{See original paper on 98}

Problematic smartphone use (PSU) is a construct involving excessive smartphone use, with accompanying negative consequences in everyday life. ${ }^{1)}$ Several scales to measure PSU have been developed and utilized. ${ }^{2-4)}$ These scales are based on the features of behavioral addiction (e.g., loss of control, tolerance, withdrawal, functional impairment, etc.). Lack of family functioning, poor peer relationship, low self-esteem, and impulsiveness were reported as key factors in causing PSU in Korean adolescents. ${ }^{5)}$ In a national survey conducted in 2018, the prevalence of smartphone overdependence was 29.3\% among Korean adolescents, which was the highest among all age groups. ${ }^{6}$ As smartphone overdependence is steadily increasing in Korean children, the Korean government is planning to implement preventive interventions at an early age to reduce the risk of smartphone overdependence. ${ }^{7)}$

It is well known that PSU is related to poor mental health such as depression, anxiety, stress, and poor sleep quality. However, the exact causal pathway of the relationship is not fully understood. Depressed Individuals may use their smartphones as a coping mechanism to deal with negative emotions. Heavy use of smartphones could impair sleep, as well as influence stress and depression. Thus, PSU may be involved in a vicious cycle with poor mental health. ${ }^{8)}$ Sohn et al. ${ }^{9)}$ reported that PSU was associated with an increased odds of depression (Odds ratio [OR], 3.17; 95\% confidence interval [CI], 2.30-4.37), increased anxiety (OR, 3.05; 95\% CI, 2.64-3.53), high perceived stress (OR, 1.86; 95\% CI, 1.24-2.77), and poor sleep quality (OR, 2.60; 95\% CI, 1.39-4.85) among children and young people. There appear to be gender differences in the pattern of smartphone use and the risk of PSU and depression. Since female adolescents have a stronger desire for social interaction, they are likely to spend more time on online chats and social networking services (SNS). Adolescents with PSU were reported to use online chats and SNS more frequently. ${ }^{10)}$ In contrast, male adolescents appear to be more interested in playing mobile game. Female adolescents are relatively vulnerable to PSU and depression. ${ }^{11,12)}$ However, Park et al. ${ }^{13)}$ reported that gender differences were not found in the strength of the relationship between mobile phone addiction and depression.

In the present issue, Kim et al. ${ }^{14)}$ investigated whether excessive smartphone use is associated with poor mental health in Korean adolescents using data from the 13th Korea Youth Risk Behavior Survey (KYRBS), 2017. The study participants consisted of 54,603 students (26,930 males and 27,673 females) from middle and high schools in Korea, who had used smartphones during the past 30 days. The results showed that excessive use of smartphones ( $\geq 30 \mathrm{~h} / \mathrm{wk}$ ) was associated with depressive symptoms (OR, 1.18; 95\% CI, 1.10-1.26), suicidal ideation (OR, 1.18; 95\% CI, 1.08-1.29), and suicidal attempt (OR, 1.34; 95\% CI, 1.11-1.60) compared to spending less time $(<16 \mathrm{~h} / \mathrm{wk})$. Previous studies have suggested that a longer duration of smartphone use is one of the most significant predictors of PSU. ${ }^{11,15)}$ However, PSU was not diagnosed in the study of Kim et al. ${ }^{14)}$ because KYRBS did not include a scale measuring PSU. It is noted that the OR of excessive smartphone use on depressive symptoms in the study of Kim et al. ${ }^{14)}$ is remarkably lower than the OR of PSU on depression in a meta-analy- 
sis of Sohn et al. ${ }^{9)}$ Not all adolescents who use their smartphones for a long-time exhibit features of behavioral addiction. Smartphones have become an integral part of daily life and the pattern of smartphone use gets diverse. While smartphone usage time is commonly measured as a proxy of PSU, measuring time spent on the smartphone may be insufficient in predicting PSU. ${ }^{16,17)}$

Social media on smartphones has both benefits and costs for adolescents. Social media may help adolescents share information, interact with peers, and develop their identities. However, adolescents' use of social media can also have negative effects including depression, social anxiety, cyberbullying, and exposure to harmful content. ${ }^{18)}$ Adolescents are vulnerable to PSU because they lack the ability to manage impulsive behaviors. ${ }^{19)}$ Korean psychiatrists recommended limiting daily usage time of smartphones during adolescence. ${ }^{20)}$ Information pertaining to the potential harm related to excessive smartphone use should be provided to adolescents and their families. Additionally, adolescents should be encouraged to use their smartphones safely and responsibly.

\section{CONFLICT OF INTEREST}

No potential conflict of interest relevant to this article was reported.

\section{ORCID}

Young Gyu Cho: https://orcid.org/0000-0003-1017-8884

\section{REFERENCES}

1. Elhai JD, Levine JC, Hall BJ. Problematic smartphone use and mental health problems: current state of research and future directions. Dusunen Adam J Psychiatry Neurol Sci 2019;32:1-3.

2. Kwon M, Lee JY, Won WY, Park JW, Min JA, Hahn C, et al. Development and validation of a smartphone addiction scale (SAS). PLoS One 2013;8:e56936.

3. Kim D, Lee Y, Lee J, Nam JK, Chung Y. Development of Korean smartphone addiction proneness scale for youth. PLoS One 2014;9:e97920.

4. Lin YH, Chang LR, Lee YH, Tseng HW, Kuo TB, Chen SH. Development and validation of the Smartphone Addiction Inventory (SPAI). PLoS One 2014;9:e98312.

5. Lee H, Kim J. A structural equation model on Korean adolescents' excessive use of smartphones. Asian Nurs Res 2018;12:91-8.

6. Ministry of Science and ICT; National Information Society Agency. The 2018 survey on smartphone overdependence [Internet]. Daegu: National Information Society Agency; 2019 [cited 2020 Mar 2]. Avail- able from: https://www.nia.or.kr/site/nia_kor/ex/bbs/View.do;JSESSI ONID=AE9A8C05E2696F214AA4B6216EB95DEF.5a07860e5eb667161 ?cbIdx=65914\&bcIdx=20876\&parentSeq=20876.

7. Comprehensive plan for prevention and resolution smartphone and internet overdependence (2019-2021) [Internet]. Sejong: Ministry of Science and ICT; 2018 [cited 2020 Mar 2]. Available from: https:// www.msit.go.kr/SYNAP/skin/doc.html?fn=239311b4felc85dlad7319 6efc4f0981\&rs=/SYNAP/sn3hcv/result/202003/.

8. Elhai JD, Dvorak RD, Levine JC, Hall BJ. Problematic smartphone use: a conceptual overview and systematic review of relations with anxiety and depression psychopathology. J Affect Disord 2017;207:251-9.

9. Sohn S, Rees P, Wildridge B, Kalk NJ, Carter B. Prevalence of problematic smartphone usage and associated mental health outcomes amongst children and young people: a systematic review, meta-analysis and GRADE of the evidence. BMC Psychiatry 2019;19:356.

10. Lee H, Kim JW, Choi TY. Risk factors for smartphone addiction in Korean adolescents: smartphone use patterns. J Korean Med Sci 2017;32:1674-9.

11. Fischer-Grote L, Kothgassner OD, Felnhofer A. Risk factors for problematic smartphone use in children and adolescents: a review of existing literature. Neuropsychiatr 2019;33:179-90.

12. McGuinness TM, Dyer JG, Wade EH. Gender differences in adolescent depression. J Psychosoc Nurs Ment Health Serv 2012;50:17-20.

13. Park SY, Yang S, Shin CS, Jang H, Park SY. Long-term symptoms of mobile phone use on mobile phone addiction and depression among Korean adolescents. Int J Environ Res Public Health 2019;16:3584.

14. Kim H, Cho MK, Ko H, Yoo JE, Song YM. Association between smartphone usage and mental health in South Korean adolescents: the 2017 Korea Youth Risk Behavior Web-Based Survey. Korean J Fam Med 2020;41:98-104.

15. Cha SS, Seo BK. Smartphone use and smartphone addiction in middle school students in Korea: prevalence, social networking service, and game use. Health Psychol Open 2018;5:2055102918755046.

16. Noe B, Turner LD, Linden DEJ, Allen SM, Winkens B, Whitaker RM. Identifying indicators of smartphone addiction through user-app interaction. Comput Human Behav 2019;99:56-65.

17. Shin M, Lee K. Measuring smartphone usage time is not sufficient to predict smartphone addiction. J Theor Appl Info Technol 2017;95: 5296-303.

18. Uhls YT, Ellison NB, Subrahmanyam K. Benefits and costs of social media in adolescence. Pediatrics 2017;140(Suppl 2):S67-S70.

19. Jo HS, Na E, Kim DJ. The relationship between smartphone addiction predisposition and impulsivity among Korean smartphone users. Addict Res Theory 2018;26:77-84.

20. Lee YJ, Lee SI, Lee AR, Bahn GH, Choi TY, Kim JY, et al. Attitudes of psychiatrists towards smartphone usage of children and adolescents. J Korean Neuropsychiatr Assoc 2015;54:556-63. 